\title{
Lateral spread of invasive Spartina alterniflora in uncrowded environments
}

\author{
Brian Dennis · Janie C. Civille • Donald R. Strong
}

Received: 4 December 2009/ Accepted: 29 June 2010/Published online: 15 July 2010

(C) The Author(s) 2010. This article is published with open access at Springerlink.com

\begin{abstract}
We present a stochastic model of clonal growth in uncrowded environments and use it to study data of 7,536 clones from the invasion of Willapa Bay, Washington by the Atlantic cordgrass Spartina alterniflora. The model incorporates effects on clone growth of covariates, spatial autocorrelation, and temporal trends. The deterministic component of the model assumes that growth rate of a clone's area is proportional to its perimeter, resulting in constant radial growth of the clone. The full stochastic model is built assuming that the fluctuations of radial growth
\end{abstract}

Electronic supplementary material The online version of this article (doi:10.1007/s10530-010-9834-4) contains supplementary material, which is available to authorized users.

\section{B. Dennis}

Department of Fish and Wildlife Resources and Department of Statistics, University of Idaho, Moscow, ID 83844-1136, USA

B. Dennis $(\square)$

Department of Fish and Wildlife Resources, University

of Idaho, Moscow, ID 83844-1136, USA

e-mail: brian@uidaho.edu

J. C. Civille

2731 Bethel St NE, Olympia, WA 98506, USA

e-mail: jciville@comcast.net

D. R. Strong

Department of Evolution and Ecology, University

of California Davis, Davis, CA 95616, USA

e-mail: drstrong@ucdavis.edu increments (differences of square root-transformed areas) are normally distributed with constant variance. Graphical fit analysis with the density probability plot technique indicates that the stochastic model provides an excellent description of the S. alterniflora invasion. Variation in Spartina growth was significantly but weakly $(5 \%)$ related to intertidal elevation, substrate type, year of survey, and the twoway interactions between these variables, suggesting that factors intrinsic to Spartina, along with localized high frequency noise, dominate the effects of larger scale abiotic factors on clone growth. Our model of clonal growth is potentially applicable to other systems with approximately circular plants or lichens.

Keywords Clonal growth model · Cordgrass invasion - Density probability plot - Spartina alterniflora - Stochastic difference equation . Stochastic growth model

\section{Introduction}

Clonal performance, defined as growth of a clone's area, volume, or biomass, is as important to invasions as is reproduction (Pan and Price 2001). It is fundamental to demographics and integrates abiotic and biotic influences upon vegetative growth and seed production (Douhovnikoff et al. 2005). For many modular organisms clonal performance before and between bouts of reproduction contributes substantially to invasion 
dynamics. For plants, clonal persistence and growth integrate rhizome and culm production, which reflect abiotic and biotic forces acting upon the invasion and which will determine the magnitude and quality of future seed production. Clonal growth, both positive and negative, is affected by environmental fluctuation and buffers complex density dependence such as that manifested in Allee effects (Davis 2004a, b). Finally, clonal performance underlies natural selection and evolution of invading species.

To help understand the relative contributions of intrinsic versus abiotic factors in clonal performance, we construct a stochastic dynamic model of clonal growth rates in uncrowded environments. The model allows assessment of the effects of environmental covariates, spatial autocorrelation, and temporal trends in growth of populations of clones. We use the model to study the invasion of Willapa Bay, Washington (WA) by the Atlantic cordgrass Spartina alterniflora, the first of many known invasions by S. alterniflora on the Pacific coast of North America (Strong and Ayres 2009).

We start with a deterministic model for the growth of $S$. alterniflora clones, and then we expand it into a stochastic version. The stochastic version makes possible various statistical inferences that are helpful for connecting the model to data (Dennis et al. 1995): parameter estimation, hypothesis tests, model evaluation. As well, the assumptions behind the stochastic growth model become testable predictions. In particular, an overall model hypothesis is that there are large regions of space and periods of time in the system for which the model provides useful descriptions of the observed clonal growth patterns. The degree of heterogeneity in clonal growth among different regions, elevations, and time periods measures the degree of influence of abiotic factors versus intrinsic factors.

Spartina alterniflora probably arrived in Willapa Bay at the end of the nineteenth century with live oyster shipments by rail from Atlantic marshes (Civille et al. 2005). The first Willapa Bay record is a 1940 photograph of a huge $S$. alterniflora clone with an estimated diameter of $42 \mathrm{~m}$. The long term historical trend of total S. alterniflora cover in Willapa Bay describes an almost straight semilog line over the eight data points from 1940 through the year 2000, with an average annual areal growth rate of about $12 \%$ (Civille et al. 2005, Fig. 3). In the year 2000, 1,670 ha of solid
S. alterniflora occupied $27 \%$, of the 6,000 ha of intertidal habitat of Willapa Bay.

Maritime cordgrasses, Spartina spp., disperse by seeds that float on the tide; there is not a seed bank and clonal fragmentation contributes little to spread of these plants (Civille et al. 2005, Strong and Ayres 2009). Each clone thus arose from a seed that arrived by floating before germination and not from clonal fragments eroded from another plant. Visible and distinct in contrast against the open mud of their intertidal habitat, cordgrass clones are circular unless fragmented and grow at lower intertidal elevations than other erect vegetation (Fig. 1, Online Resource 1). Widely separated clones at the leading edge of invasions grow for years and even decades before coming in contact with another clone. Each clone has sprung from a seed germinating upon the mud. Radiating outward, rhizomes give rise to culms that grow to heights of $1 \mathrm{~m}$ or more.

Spartina growth defines and maintains the shoreline along broad expanses of temperate coasts (Strong and Ayres 2009). As a result of growing lower in the intertidal zone than other vascular plants, Spartina can alter the physical, hydrological, and ecological environments of estuaries. Where native, Spartina is uniformly valued for the ability to hold and define the shoreline. For at least 500 years, Spartina has been spread around the world by humans, probably mostly on purpose. Where it is not native, Spartina is now mostly considered to be a bane. The tendencies of elevating shorelines to the point of transforming salt marsh into terrestrial habitat, of overgrowing native plants, threatening native animals, and of hybridizing with native Spartina species are what makes these

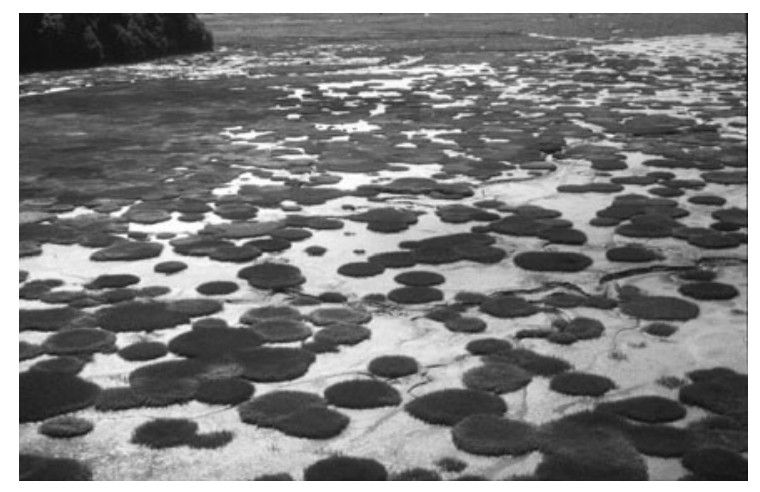

Fig. 1 Near-circular clones of Spartina alterniflora at Needle Point, Willapa Bay, north Pacific County, WA $\left(46^{\circ} 30^{\prime} 46^{\prime \prime} \mathrm{N}\right.$, $\left.123^{\circ} 55^{\prime} 10^{\prime \prime} \mathrm{W}\right)$. Photo by Fritzi Grevstad 
plants unwelcome invaders (Sloop et al. 2009; Ding et al. 2008; Nordby et al. 2009).

\section{Data}

The data consisted of the surface areas and spatial coordinates of 7,536 distinct $S$. alterniflora clonal individuals (Online Resource 2). One group of 2,715 clones was measured in 1994 and 1997, a second group of 4,237 clones was measured in 1997 and 2000, and a third group of 584 clones was measured in 1994, 1997, and 2000. The first two groups were combined into a data set termed "growth rate data" in the analyses. The third group was measured in all 3 years and is called "repeated measures data" in the analysis.

The data were extracted from high resolution aerial photography of 22 intertidal areas ranging over the entire $45 \mathrm{~km}$ north-south length and ca $7.5 \mathrm{~km}$ maximum width of Willapa Bay, WA. In decimal degrees, Willapa bay covers ca $46.37^{\circ}$ to $46.75^{\circ}$ and -124.380 to $-124.10^{\circ}$ (in decimal degrees, north and east are + ). Color infrared photography is preferred for studies of marsh vegetation because it provides clear delineation between vegetation, water, and the wet intertidal substrates in this study (Civille et al. 2005). Infrared radiation is strongly absorbed by water but strongly reflected by healthy vegetation. The color infrared photographs were made from fixed-wing aircraft during surveys made by the state of Washington in 1994, 1997, and 2000. Scanning, orthorectification, and data processing followed Civille et al. (2005). Positional accuracy was calculated in relation to black and white digital orthophotographs from 1992 produced by the Washington Sate Department of Natural Resources Photogrammetry Unit; the reference orthophotographs had positional errors (RMSE) less than $1 \mathrm{~m}$, with $39 \mathrm{~cm} \times 39 \mathrm{~cm}$ pixels.

Spartina alterniflora is easy to distinguish from mud and sand on the tide flats and from other salt marsh plants in properly exposed color infrared images (Online Resource 1). The flats are usually dark grey to blue in color; the native marsh is soft light pink, while S. alterniflora is dark, saturated orange-red. The S. alterniflora clones in this study had the characteristic circular growth pattern that cordgrass displays when growing at low density on open intertidal mud (Davis et al. 2004a, b). A combination of supervised and unsupervised classification and clustering techniques
(Richards and Jia 2006) was used to statistically group pixels of similar spectral reflectance values into a simple binary classification scheme of Spartina: Not-Spartina. The final binary rasters were converted to ESRI ArcInfo polygon coverages, and imported to ArcInfo software. After the polygon coverage was produced, we filtered the polygons and excluded those smaller than $1 \mathrm{~m}^{2}$, which is slightly less than 9 clustered pixels $\left(1.17 \mathrm{~m}^{2}\right)$ to be certain that we were only including $S$. alterniflora plants in our data (Wilkie and Finn 1996). Sizes (areas in $\mathrm{m}^{2}$ ) were calculated from the pixel counts for each individual.

The three groups of clones mentioned earlier were constructed from the images as follows. Each clone in the first group was in a polygon on the 1994 images that was isolated from other S. alterniflora and that intersected with 1 and only $1 S$. alterniflora-containing polygon at the identical point in space on the 1997 image. The second group was similarly formed from the 1997 and 2000 images. No individuals from the second group spatially overlapped those in the first group. The clones in the third group were in unique $S$. alterniflora-containing polygons, which were separate from other $S$. alterniflora-containing areas, and with overlapping geographic spots in the 1994, 1997, and 2000 images.

Elevation was measured by single-return, nonpenetrating LiDAR with independent ground truthing conducted by a licensed land surveyor on relatively flat bare ground around Willapa Bay. The data were collected during three $24 \mathrm{~h}$ periods chosen for the lowest tide, day or night, from March 26 until April 24, 2002. The raw LiDAR data are available at http:// www.onrc.washington.edu/mdai/noaa_csc_willapa_ bay.htm. These LiDAR data were combined by means of a digital elevation model with the orthorectified images of the substrate and S. alterniflora. The substrate types in 21 sub-regions of Willapa Bay where $S$. alterniflora grew were determined by direct observation (Civille et al. 2005; Civille 2006).

\section{The model}

\section{Deterministic model}

We used spatial area of an individual as the basic state variable, because measuring the area in the form of a pixel count from the digitized aerial photos was 
straightforward. Let $A_{t}$ denote the area covered by an individual at time $t$. Area growth only occurs at the edge of an individual, and we assumed that each unit length of perimeter of an individual can contribute a constant amount of area growth in a unit of time. Perimeter is proportional to the square root of area, and so we formulated the growth of area as.

$\frac{d A_{t}}{d t}=\frac{1}{2} \mu A_{t}^{1 / 2}$.

Here $\mu$ is a positive constant. The factor of $1 / 2$ just eliminates a factor of 2 in the subsequent formulas. By integrating, using initial condition $A_{0}$ at time $t=0$, we find that.

$A_{t}^{1 / 2}=\mu t+A_{0}^{1 / 2}$.

The initial condition, $A_{0}$ is the spatial area of the first sprout from a seed and is close to zero. Both perimeter and radius are proportional to the square root of area, so Eq. 2 implies that perimeter and radius grow linearly with time. Let $P_{t}=A_{t}^{1 / 2} ; P_{t}$ represents a transformation of area into a surrogate for perimeter or radius. Equation 2 also implies that growth increments of $P_{t}$, calculated at discrete times corresponding to data collected at regular time intervals, are constant:

$P_{t}-P_{t-1}=\mu$.

We term $P_{t}-P_{t-1}$ a radial growth increment. Equation 3 is the deterministic model for the radial growth of Spartina clones and constitutes a central hypothesis of our study.

\section{Stochastic model}

Connecting the growth model (Eq. 3) to data was accomplished by adding a stochastic component to account for the departures of observations from model predictions. If, on average, clonal growth increments are constant on the square root scale, we surmised that variability in the increments might be constant on the square root scale as well. Accordingly, our stochastic model adds a "noise" term to each radial growth increment:

$P_{t}-P_{t-1}=\mu+\sigma Z_{t}$,

where $Z_{t}$ has a normal distribution with a mean of 0 and a variance of $1\left(Z_{t} \sim \operatorname{normal}(0,1)\right)$, with $Z_{1}$, $Z_{2}, \ldots$ uncorrelated. Here $\sigma$ is a positive constant representing the standard deviation of the fluctuations in the increments. Equation 4 implies that $P_{t} \sim$ normal $\left(\mu t, \sigma^{2} t\right)$. The model for $P_{t}$ is identical to discretetime Brownian motion with constant drift rate $\mu$ (Allen 2005).

The normal distribution in the stochastic growth model (Eq. 4) allows the possibility of negative growth increments. The remotely sensed data do indeed contain occasional observations of decreasing pixel counts for individuals (Data, above). The deterministic portion of the model captures the tendency for individuals to increase. The stochastic portion, to be useful for inferences, should be constructed to describe the departures of data from the deterministic portion accurately.

The assumptions behind the stochastic growth model can be recast as testable predictions. The radial growth increments of individuals are predicted to have constant mean and variance, to be normally distributed, and to be uncorrelated through time. An overall model hypothesis is that there are large regions of space and periods of time in the system for which these model properties are useful descriptions of the observed growth patterns. If the hypothesis is adequate, the model can be used to identify and quantify the degree of heterogeneity in growth among those different regions and time periods at larger scales. As well, the model can help toward estimating the degree of spatial dependence in growth rates among individuals.

Statistical methods

With regard to the model predictions, we were especially interested in four questions: (1) How adequate was the growth model for describing the growth rate data? (2) What were the effects of different covariates (predictor variables) on growth rates, and did such effects interact? (3) What was the degree and nature of spatial correlation in growth rates among individuals? (4) How much did growth in the two time periods change for individuals for which growth was recorded in both intervals? For questions 1-3, we analyze the "growth rate data" set in which some clones were sampled in 1994-1997 and some in 1997-2000. For question 4, we restricted analyses to the "repeated measures data" consisting of clonal individuals that had growth rates measured across both time periods. 
All analyses used the square root transformation of the individual clonal areas. "Growth rate" refers in our descriptions to the radial growth increment (difference of square root-transformed areas of a clonal individual) in a 3 year time period and is the basic response variable in the analyses.

To address question 1 (adequacy of the model), we used the "density probability plot" (Jones and Daly 1995; Jones 2004) as a key diagnostic tool for evaluating the model and detecting departures from normality. The density probability plot is an effective graphical tool for assessing goodness of fit of a continuous distribution model (Jones 2004) and is related to the more familiar probability plot. Let $Y$ be a random variable with a continuous probability distribution, and let $F(y)$ and $f(y)$ denote, respectively, the cumulative distribution function (cdf) and probability density function (pdf) of the model to be assessed. Let $y_{(1)}, y_{(2)}, \ldots, y_{(q)}$ denote the data from the random process, ordered from smallest to largest. The usual probability plot is a scatter plot of $F^{-1}\left(\frac{i-0.5}{q}\right)$ versus $y_{(i)}(i=1,2, \ldots, q)$, with any parameters in the cdf evaluated at their estimated values. A straight line indicates good fit, but the problem with the probability plot is that departures from fit, while easily detected, are not easily interpreted. The density probability plot by contrast is a scatter plot of $f\left(F^{-1}\left(\frac{i-0.5}{q}\right)\right)$ versus $y_{(i)} \quad(i=1$, $2, \ldots, q)$, superimposed on a continuous plot of the pdf curve $f(y)$, with any unknown parameters in the cdf and pdf set at their estimated values. Figure 2 displays examples of what to expect visually when the fit is good and when the fit is bad. Departures from fit are easy to interpret, as illustrated by using a normal distribution to describe data simulated from a Student's $t$ distribution (Fig. 2).

To fit the model to all the data, or to the data from a single region or time interval, we used the sample mean and sample variance of the growth rates as the estimates of the unknown parameters $\mu$ and $\sigma^{2}$. Under the model, the sample mean is the maximum likelihood estimate of $\mu$, and the sample variance is the maximum likelihood estimate of $\sigma^{2}$ corrected for bias (Rice 1995), provided the stochastic fluctuations of the growth rates among clonal individuals are independent. Such assumptions were examined with spatial and temporal analyses (below).
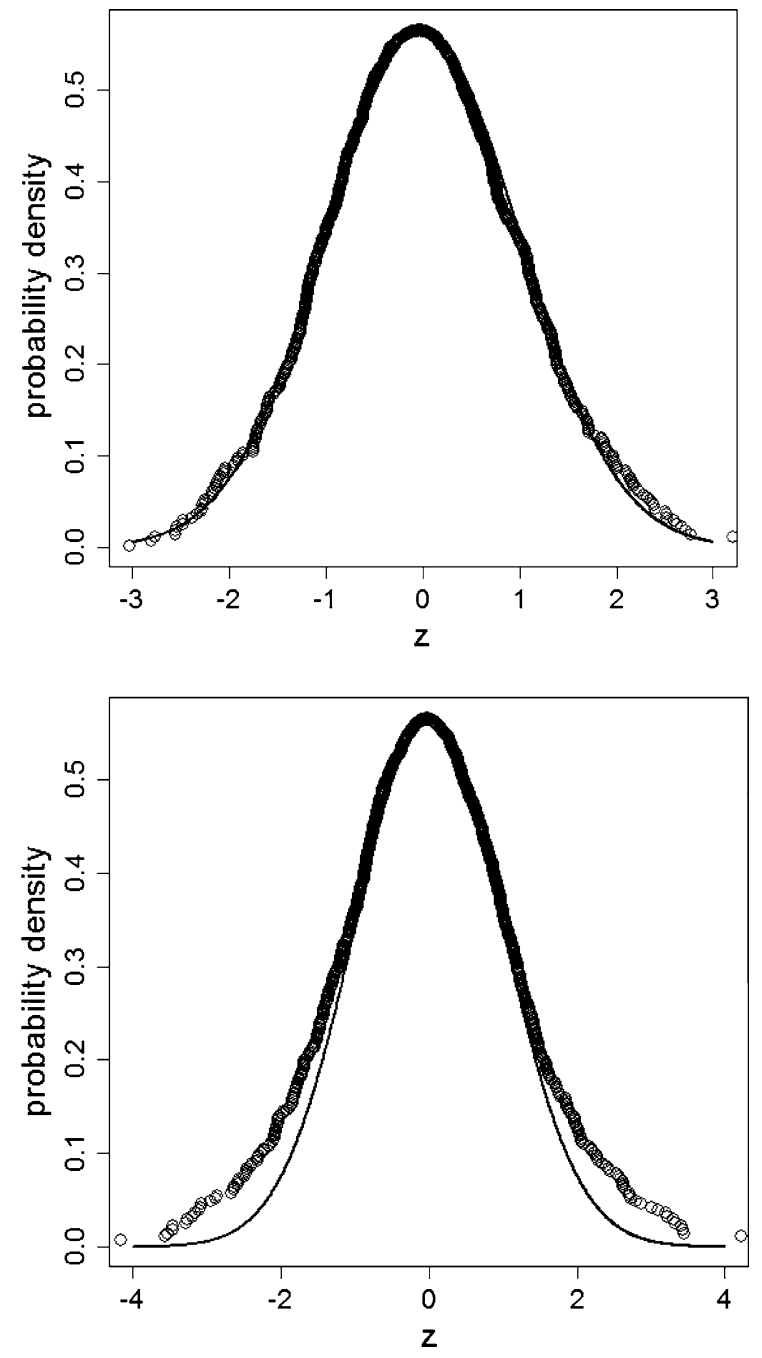

Fig. 2 Top Density probability plot for a standard normal distribution, using 1,000 observations simulated from a standard normal distribution, showing the appearance of the plot when the fit is good. Bottom Density probability plot for a standard normal distribution, using 1,000 observations simulated from a Student's $t$ distribution with 10 degrees of freedom, showing the appearance of the plot when the data originate from a heavier-tailed distribution

For question 2 (effects of environmental covariates), we were interested specifically in estimating differences in mean growth for plants at different marsh elevations, substrates or time periods. Such differences correspond to a model with different values of $\mu$ for those elevations, substrates or periods. We examined differences in growth due to elevation ( $\mathrm{m}$ above or below mean sea level), substrate type 
(mud, sand), and time period (1994-1997, 1997-2000) by writing $\mu$ in Eq. 4 as a linear statistical function:

$\mu=\boldsymbol{x}^{\prime} \boldsymbol{\beta}$.

Here $\boldsymbol{x}$ is a column vector of covariates measured for a clonal individual, and $\boldsymbol{\beta}$ is a column vector of unknown parameters. Various statistical inferences then reduce to standard procedures under the normal linear statistical model for analysis of covariance, calculated using the growth rates as the response variable, with categorical (indicator variables) or numerical covariates included in $\boldsymbol{x}$. We thus searched for combined effects of the categorical predictors (substrate, time period) and elevation with conventional analysis of covariance (Ott and Longnecker 2001). Calculations were performed using SAS (SAS Institute Inc. 2003).

For question 3 (degree of spatial dependence), we examined the data for the degree of spatial autocorrelation in the growth rates. Using spatial coordinates of 2,540 clonal individuals from the 1994-1997 growth rate data ("spatial data," Online Resource 2), we calculated a variogram (Cressie 1991, p. 69) of the growth rates. For each pair of individuals, the distance between them was calculated. The distances were then categorized into distance interval bins, and the average squared difference of the growth rate pairs was calculated within each bin. We tried various different bin widths for the distances; the large number of observations supported stable estimation on a relatively fine spatial scale having $6 \mathrm{~m}$ bin widths, with a minimum distance of $3 \mathrm{~m}$. A variogram constitutes an estimate of the variance of the growth rate difference for individuals separated by a given distance; such variance is lower when the growth rates are correlated. A variogram in principle rises from zero as a function of distance, becoming level at and beyond the distance at which observations become uncorrelated. Variogram calculations were programmed in the $\mathrm{R}$ language (R Core Development Team 2006).

Question 4 (change of growth rates over time for individuals) was addressed with the repeated measures data set. The repeated measures data allowed us to look for temporal differences and correlations in growth in the same clonal individuals in the fashion of a longitudinal study. We used the difference of growth rates as the response variable (1997-2000 growth minus 1994-1997 growth) for a clonal individual, in order to estimate the difference of growth rates with paired observations. We sought to explain variability in the differenced growth rates in terms of predictor variables (substrate, elevation). Finally, we estimated correlation of the 1994-1997 growth rate with the 1997-2000 growth rate for clonal individuals. Calculations were performed with SAS (SAS Institute Inc. 2003).

\section{Results}

\section{Question 1}

For such a large number of observations, the simple two-parameter normal distribution model captured the pattern of variability remarkably well (Fig. 3, top). Parameter estimates were $\hat{\mu}=2.05, \hat{\sigma}^{2}=5.50$. Thus, on average a clonal individual increased in radius about $\hat{\mu} \pi^{-1 / 2}=1.56 \mathrm{~m}$ in 3 years, with a "typical departure" from that radius increase of approximately $\sqrt{\hat{\sigma}^{2}} \pi^{-1 / 2}=1.32 \mathrm{~m}$. Thus, the $42 \mathrm{~m}$ diameter Spartina patch in the 1940 photo ("Introduction") is estimated by the simple two-parameter model to have been growing for $3(42) /[2(1.56)]=$ 40.4 years, consistent with the hypothesis that it colonized during the early years of the Willapa Bay oyster industry, at the end of the nineteenth century. Also, under the model the estimated probability of negative growth, that is, the area under a normal $\left(\hat{\mu}, \hat{\sigma}^{2}\right)$ density curve to the left of zero, was 0.19 , closely approximating the empirical proportion, 0.18 , of negative growth rates in the data.

\section{Question 2}

The resulting linear model for the growth rate data was of the form

$$
\begin{aligned}
Y= & \beta_{0}+\beta_{1} x_{1}+\beta_{2} x_{2}+\beta_{3} x_{3}+\beta_{4} x_{1} x_{2}+\beta_{5} x_{1} x_{3} \\
& +\beta_{6} x_{2} x_{3}+\varepsilon,
\end{aligned}
$$

where $Y$ is the growth rate $\left(P_{t}-P_{t-1}\right.$, with 1 time unit $=3$ years) for a clonal individual, $x_{1}=$ elevation $(\mathrm{m}$, centered at $\bar{x}=2.277 \mathrm{~m}$ above mean sea level), $x_{2}=$ time period indicator (+1: 1994-1997, -1 : 1997-2000), and $x_{3}=$ substrate indicator $(+1$ : sand, -1 : mud), and $\varepsilon \sim$ normal $\left(0, \sigma^{2}\right)$, with parameter estimates (and $P$-values) given by $\hat{\beta}_{0}=2.14$ $(<0.0001), \hat{\beta}_{1}=-0.671(<0.0001), \hat{\beta}_{2}=0.496$ 

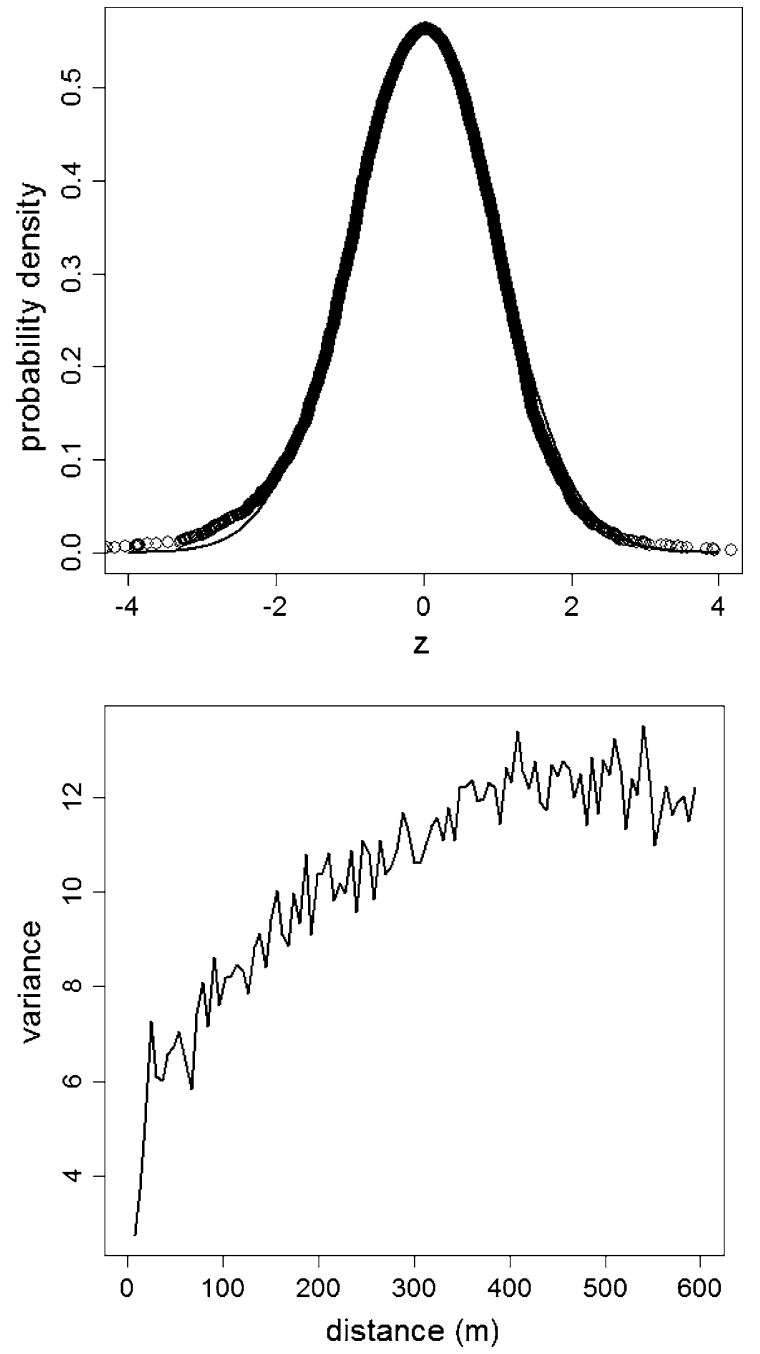

Fig. 3 Top Density probability plot for a standard normal distribution, using standardized growth rates (differences of square root-transformed clonal areas over 3 years period) for 6,952 clonal individuals of $S$. alterniflora in Willapa Bay, WA. Bottom Spatial variogram of growth rates for 2,540 pairs of clonal individuals of $S$. alterniflora in Willapa Bay, WA. Variogram height is the sample mean of the squared differences of growth rates for pairs in a distance bin $(6 \mathrm{~m}$ bin width, minimum distance of $3 \mathrm{~m}$ ), and horizontal axis is sample mean of distances for the pairs in that bin

$(<0.0001), \hat{\beta}_{3}=-0.147(<0.0001), \hat{\beta}_{4}=-0.210$ (0.0028), $\quad \hat{\beta}_{5}=-0.520(<0.0001), \quad \hat{\beta}_{6}=0.0612$ $(0.0639), \quad \hat{\sigma}^{2}=5.23$. The pairwise product terms quantify two-way interactions; a three-way interaction term and a quadratic altitude term were not significant and were dropped from the model.

The parameters $\beta_{1}, \beta_{2}, \ldots, \beta_{6}$ are interpreted as effect sizes (departures from a grand mean growth rate). The intercept is the estimated grand mean growth rate at the centered elevation of 0 (uncentered elevation of $2.277 \mathrm{~m}$ above mean sea level). Thus, on average a clonal individual at that elevation would show an increase in radius of around $\hat{\beta}_{0} \pi^{-1 / 2}=$ $2.14 \pi^{-1 / 2}=1.21 \mathrm{~m}$ in 3 years. The mean radius increase of $1.56 \mathrm{~m}$ in the earlier 2-parameter model does not reflect the adjustments of covariates. The relationship of growth rate to elevation was negative; each $\mathrm{m}$ of elevation produces an average change of $\hat{\beta}_{1} \pi^{-1 / 2}=-0.671 \pi^{-1 / 2}=-0.379 \mathrm{~m}$ in radius growth over 3 years. Growth rate was higher in the early time period (1994-1997) by an average of $\hat{\beta}_{2} \pi^{-1 / 2}=$ 0.280 m over the grand mean at the centered elevation of 0 . The relationship of growth rate and elevation had a steeper negative slope in the early period than in the later period, with each $\mathrm{m}$ of elevation changing the grand mean radius growth by an average of $\left(\hat{\beta}_{1}+\hat{\beta}_{4}\right) \pi^{-1 / 2}=-0.497 \mathrm{~m}$. Growth rate was lower in sand, with an average of $\hat{\beta}_{3} \pi^{-1 / 2}=-0.0829 \mathrm{~m}$ change to the grand mean at the centered elevation of 0 . Also, the effect of elevation on growth rate had a steeper negative slope in sand than in mud, with each $\mathrm{m}$ of elevation in sand changing the grand mean radius growth by an average of $\left(\hat{\beta}_{1}+\hat{\beta}_{5}\right) \pi^{-1 / 2}=$ $-0.672 \mathrm{~m}$. The categorical variables substrate and time period had an interactive effect of borderline statistical significance; growth rate in sand during the early time period was slightly larger $\left(\hat{\beta}_{6} \pi^{-1 / 2}=\right.$ $0.0345 \mathrm{~m}$ ) than the mean growth rate in sand.

While the effects of elevation, substrate, and time period were deemed highly significant by statistical tests (above $P$-values), the size of the effects was small compared to the total variability in the growth rate data. For the fitted linear model (Eq. 6), the covariates and their interactions accounted for only about $5 \%$ of growth rate variability $\left(R^{2}=0.0505\right)$. The large number of observations in the data made it possible to detect small effects. As a result, the residuals from the fitted linear model were almost as variable as the original growth rate data.

\section{Question 3}

Some degree of spatial autocorrelation was evident. The variogram of the growth rate data leveled at around $360 \mathrm{~m}$ distance between plants (Fig. 3, 
bottom). Below $360 \mathrm{~m}$, the correlation of the growth rates increased (variogram decreased) for decreasing distances between plants, with little or no appearance of a "nugget" (positive vertical axis intercept, usually caused by measurement or sampling error in the data). Growth rates of plants separated by more than $360 \mathrm{~m}$ were essentially uncorrelated.

\section{Question 4}

The repeated measures data set revealed that mean growth for clonal individuals in the 1994-1997 period was greater than mean growth in the 19972000 period (paired $T=10.7, P<0.0001$ ). Mean growth in the first period was positive, while mean growth in the second period was actually negative: $\hat{\mu}_{1}=2.09 \quad\left(\hat{\sigma}_{1}^{2}=10.1\right), \hat{\mu}_{2}=-1.22\left(\hat{\sigma}_{2}^{2}=38.1\right)$. The variability of the growth rates compared to the means was large in both periods (152 and 504\% coefficients of variation, respectively). The difference of means was estimated at -3.31 , with a $95 \%$ confidence interval, using paired differences, of $(-3.92,-2.71)$. Although the difference of means was statistically significant, it was small compared to the variability of the differences among plants $(226 \%$ coefficient of variation). In addition, the 1994-1997 and 1997-2000 growth rates of clonal individuals were correlated, but only slightly $(R=0.199$, $P<0.0001)$. The analysis of the effects of covariates on the growth rate differences using normal linear statistical models revealed significant effects of substrate and elevation, along with a significant interaction. The results were in agreement with the results of the linear model analysis reported above for the growth rate data set. The repeated measures data were as noisy as the growth rate data: while the effects of the covariates were detectable, the fitted linear model accounted for only about $6 \%$ of the variability in the growth rate differences.

\section{Discussion}

The testable predictions of the simple two-parameter stochastic model were largely borne out. The lateral growth increments of clonal individuals had nearly constant mean and variance, were well-described by a normal distribution, and were negligibly correlated through time. The spatial and temporal extent of the data indicate that there were large areas of Willapa Bay and long periods of time in the system for which the model described the observed growth patterns of S. alterniflora in uncrowded conditions.

The effects of environmental covariates recorded in the study were nearly negligible. While statistically significant effects on growth rate were found for substrate type, elevation above mean sea level, and time period, along with interactions, the magnitudes of these effects were quite small. The large number of observations in the data permitted detection of combined covariate effects that accounted for only $5 \%$ of the variability in the growth rate data.

The spatial autocorrelation detected in our analysis suggests that clonal individuals within $360 \mathrm{~m}$ of each other have similar environmental conditions for growth, but at greater distances, the environment becomes heterogeneous with regard to growth in essentially unpredictable ways. This spatial scale is basically one dimensional in the sense of a clone's location location along a shoreline; a clone's growth rate co-varies with the growth rates of clones on the nearby shoreline, but not with those of clones, say, $500 \mathrm{~m}$ in either direction long the shore or of clones across the Bay.

The localized scale of spatial autocorrelation is a likely outcome of the physical nature of the shoreline environment. Wave actions, tides, and water-borne debris can have direct mechanical effects on clonal individuals. Sediment favorable to growth can be deposited or removed from the areas adjacent to an individual. Such environmental driving variables have inherent local unpredictability along the Willapa Bay shoreline. A large scale landscape of mudflats being encroached at a seemingly constant rate by growing S. alterniflora patches is, up close, a statistical ensemble of randomly varying local processes.

Previous efforts to model growth of approximately circular organisms have focused on Arctic/Subarctic cushion plants and Arctic lichens (Benedict 1989; Frenot et al. 1993, Molau 1997; Winchester and Chaujar 2002; McCarthy 1999, 2003; le Roux and McGeoch 2004). A significant objective of that work was the establishment of reliable "lichenometric" methods for aging the organisms. The analyses have frequently shown that simplistic assumptions that disregard biological factors, ignoring in particular the spatial and temporal variability of growth rates due to local differences in habitat, climate, and competition 
reduce the reliability of the age estimates (Winchester and Chaujar 2002; McCarthy 2003; le Roux and McGeoch 2004).

As opposed to the highly heterogeneous habitats in which some approximately circular plants grow, such as the subantarctic cushion plant, Azorella selago (le Roux and McGeoch 2004), the arctic-alpine cushion plant, Diapensia lapponica, and the lichen Rhizocarpon agg. (McCarthy 2003), that of invasive Spartina is homogenous open mud. This is the most like reason that the contributions of substrate and even intertidal level made such a proportionally small contribution to radial growth rate variation.

With our model, environmental factors could potentially be incorporated as covariates toward improved age estimation. For example, the estimated age of the large Spartina clone in the 1940 photograph could have been adjusted for the effects of environmental covariates if the covariates had a substantial effect on clonal growth. We also point out that the way we calculated the age estimate needs statistical improvement. Proper use of size growth models for age estimation must deal with the fact that predicting age from size is different from predicting size from age, that is, the ages of clones of a given size are themselves random variables. A full statistical account of lichenometrics would likely resemble first-passage time estimation in population viability analysis (i.e. amount of time until a population reaches a given size; see Dennis et al. 1991).

The clonal growth described by our model accounts for the spatial and temporal scales on which uncrowded, density independent, individual plants increase in size. This increase in radius is essentially linear and normally distributed. While our study concerned the invasion of an estuary where $S$. alterniflora is not native, it should apply to the many other estuaries around the world where these plants have invaded (Strong and Ayres 2009). Our model should also apply to the uncrowded clonal growth component of the recolonization of native areas when cordgrass regains ground lost to environmental disturbance such as cold snaps, hurricanes, or shifting substrate. The unimpeded growth described by our model does not continue indefinitely, of course. It slows when an individual eventually reaches the edge of suitable substrate or when clonal individuals grow into each other and merge into large mats. Then, growth becomes negatively density dependent, with space being a limiting resource. The modifications to hydrologic flow, porewater salinity, light availability and sediment NH4 caused by large $S$. alterniflora plants cause powerful density dependence, and almost all seedling recruitment occurred on open mud away from established plants (Lambrinos and Bando 2008). The next component of S. alterniflora spread on the landscape is the spread of seeds that disperse by floating on the tide. Intensive observation efforts demonstrated virtually no spread by rhizome fragments (Davis et al. 2004a). Nonhybrid Spartina is largely if not obligately outcrossing and wind pollinated, and the spread of Spartina genes is influenced by both pollen and seed dispersal (Davis et al. 2004b). In San Francisco Bay, $S$. alterniflora introduced from the Atlantic has hybridized with native $S$. foliosa to produce self fertilizing hybrids that spread much more rapidly than outcrossing native species (Sloop et al. 2009).

The present model of clonal individual growth is part of a larger model for predicting the spread of $S$. alterniflora on the landscape. By identifying the scale on which uncrowded growth is essentially linear and normally distributed, the present results should provide a useful benchmark for the larger model. Two additional components of $S$. alterniflora spread contribute to the complete model. First, unimpeded growth of a given clonal individual cannot continue indefinitely. Either an individual eventually reaches the edge of suitable substrate, or, nearby clonal individuals grow into each other, merging into large mats. The growth becomes negatively density dependent, with space being a limiting resource. Second, new individuals colonize vacant areas as seeds. The formation of seeds, mostly from within the largest coalesced mats, and dispersal of seeds, mostly by water, greatly increase the rate of spread of the plant across the landscape. Seed formation is enhanced in larger mats, producing positive density dependence, which is a weak Allee effect (Davis et al. 2004b). An adequate understanding of these two components of S. alternifora spread will necessarily feature a blend of biological and stochastic mechanisms (Taylor et al. 2004). $S$. alterniflora is a powerful ecosystem engineer (Neira et al. 2007) that severely disrupts the trophic structure of intertidal estuarine lands (Levin et al. 2006). The removal of $S$. alterniflora from Willapa Bay by mechanical and chemical treatments is reopening 
intertidal lands to shorebirds and waterfowl (Patten and O'Casey 2007) as well as to fishing and recreation (Murphy 2006).

Acknowledgments This work was supported by NSF Award \# 0083583 and grants from the Washington Dept. of Natural Resources and the Columbia Pacific Resources Center to D.R.S. The authors are grateful for the many fine suggestions for improving the manuscript made by two anonymous referees.

Open Access This article is distributed under the terms of the Creative Commons Attribution Noncommercial License which permits any noncommercial use, distribution, and reproduction in any medium, provided the original author(s) and source are credited.

\section{References}

Allen LJS (2005) An introduction to stochastic processes with applications to biology. Prentice Hall, Upper Saddle River

Benedict JB (1989) Use of Silene acaulis for dating: the relationship of cushion diameter to age. Arctic Alpine Res 21:91-96

Civille JC (2006) Invasion ecology and pattern assessed through remote sensing: Spartina alterniflora in Willapa Bay, Washington. Ph.D. Dissertation, University of California, Davis

Civille JC, Sayce K, Smith SD, Strong DR (2005) Reconstructing a century of Spartina alterniflora invasion with historical records and contemporary remote sensing. Ecoscience 12:330-338

Cressie N (1991) Statistics for spatial data. John Wiley, New York

Davis HG, Taylor CM, Civille JC, Strong DR (2004a) An Allee effect at the front of a plant invasion: Spartina in a Pacific estuary. J Ecol 92:321-327

Davis HG, Taylor CM, Lambrinos JG, Strong DR (2004b) Pollen limitation causes an Allee effect in a wind-pollinated invasive grass (Spartina alterniflora). Proc Natl Acad Sci USA 101:13804-13807

Dennis B, Munholland PL, Scott JM (1991) Estimation of growth and extinction parameters for endangered species. Ecol Monogr 61:115-143

Dennis B, Desharnais RA, Cushing JM, Costantino RF (1995) Nonlinear demographic dynamics: mathematical models, statistical methods, and biological experiments. Ecol Monogr 65:261-281

Ding JQ, Mack RN, Lu P et al (2008) China's booming economy is sparking and accelerating biological invasions. Bioscience 58:317-324

Douhovnikoff V, McBride JR, Dodd R (2005) Salix exigua clonal growth and population dynamics in relation to disturbance regime variation. Ecology 86:446-452

Frenot Y, Gloaguen J-C, Picot G, Bougère J, Benjamin D (1993) Azorella selago Hook used to estimate glacier fluctuations and climatic history in the Kerguelen Islands over the last two centuries. Oecologia 95:140-144
Jones MC (2004) Hazelton ML (2003) “A graphical tool for assessing normality," The American Statistician, 57, 285288: comment by Jones and reply. Am Stat 58:176-177

Jones MC, Daly F (1995) Density probability plots. Commun Stat B-Simul 24:911-927

Lambrinos JG, Bando KJ (2008) Habitat modification inhibits conspecific seedling recruitment in populations of an invasive ecosystem engineer. Biol Invasions 10:729-741

le Roux PC, McGeoch MA (2004) The use of size as an estimator of age in the subantarctic cushion plant, Azorella selago (Apiaceae). Arct Antarct Alp Res 36:608-616

Levin LA, Neira C, Grosholz ED (2006) Invasive cordgrass modifies wetland trophic function. Ecology 87:419-432

McCarthy DP (1999) A biological basis for lichenometry? J Biogeogr 26:379-386

McCarthy DP (2003) Estimating lichenometric ages by direct and indirect measurement of radial growth: a case study of Rhizocarpon agg at the Illecillewaet Glacier, British Columbia. Arct Antarct Alp Res 35:203-213

Molau U (1997) Age-related growth and reproduction in Diapensia lapponica, an Arctic-alpine cushion plant. Nord J Bot 17:225-324

Murphy KC (2006) Progress of the 2006 Spartina Eradication Program. Report to the Legislature. AGR PUB 850-180 (N/1/07). Washington State Department of Agriculture. Olympia, WA

Neira C, Levin LA, Grosholz ED (2007) Influence of invasive Spartina growth stages on associated macrofaunal communities. Biol Invasions 9:975-993

Nordby JC, Cohen AN, Beissinger SR (2009) Effects of a habitat-altering invader on nesting sparrows: an ecological trap? Biol Invasions 11:565-575

Ott RL, Longnecker M (2001) An introduction to statistical methods and data analysis, 5th edn. Duxbury Pacific Grove, California

Pan JJ, Price JS (2001) Fitness and evolution in clonal plants: the impact of clonal growth. Evol Ecol 15:583-600

Patten K, O'Casey C (2007) Use of Willapa Bay, Washington, by shorebirds and waterfowl after Spartina control efforts. J Field Ornithol 78:395-400

R Core Development Team (2006) R: a language and environment for statistical computing. R Foundation for Statistical Computing, Vienna, Austria

Rice JA (1995) Mathematical statistics and data analysis, 2nd edn. Wadsworth, Belmont

Richards JA, Jia X (2006) Remote sensing digital image analysis: an introduction. Springer, Berlin

SAS Institute Inc (2003) SAS OnlineDoc ${ }^{\circledR}$, Version 9. Cary, North Carolina

Sloop CM, Ayres DR, Strong DR (2009) The rapid evolution of self-fertility in Spartina hybrids (Spartina alterniflora $\times$ foliosa) invading San Francisco Bay, CA. Biol Invasions 11:1131-1144

Strong DR, Ayres DA (2009) Spartina introductions and consequences in salt marshes: arrive, survive, thrive, and sometimes hybridize. In: Silliman BR, Grosholz T (eds) Salt marshes under global siege, Pp. 1-22. University of California Press, Berkeley, California, 413 pp

Taylor CM, Davis HG, Civille JC, Grevstad FS, Hastings A (2004) Consequences of an Allee effect in the invasion of 
a Pacific estuary by Spartina alterniflora. Ecology 85: 3254-3266

Wilkie DS, Finn JT (1996) Remote sensing imagery for natural resource monitoring: a guide for first-time users. Columbia University Press, New York
Winchester V, Chaujar RK (2002) Lichenometric dating of slope movements, Nant Ffrancon, North Wales. Geomorphology 47:61-74 